\title{
Spectral Analysis of the EEG in Craniocerebral Trauma
}

\author{
Richard J. Moulton, Anthony Marmarou, Jacob Ronen, John D. Ward, Sung Choi, \\ Harry A. Lutz, Steven Byrd, Antonio Desalles, Angelo Maset, \\ J. Paul Muizelarr and Harold F. Young
}

\begin{abstract}
The objectives of the present study were to evaluate the relationship between the fractional amplitudes of the EEG derived from power spectral analysis (PSA) of the electroencephalogram (EEG) and depth of coma measured clinically with the Glasgow Coma Score, and to assess the accuracy of PSA in predicting long-term outcome. Thirty-two patients rendered unconscious by blunt head injury (mean $(\mathrm{GCS}=7)$ had intermittent EEG recordings daily from 1-10 days post injury. There was a significant correlation between fractional amplitude of the EEG and the GCS. The rate and magnitude of change in the EEG and GCS were also correlated. There were significant differences in PSA parameters between improved and deteriorated patient groups at the termination of monitoring $(\mathrm{p}=.02)$ and in the change of PSA parameters over time $(\mathrm{p}=.02)$. Using linear discriminant analysis of PSA parameters, the accuracy of outcome prognostication based on the six month outcome was approximately $75 \%$. Accurate classification of outcome was possible in a number of patients in whom there was little or no change in the GCS during the period of monitoring.
\end{abstract}

RÉSUMÉ: Analyse spectrale de l'EEG dans les traumatismes crâniocérébraux. L'objectif de la présente étude était d'évaluer la relation entre les amplitudes fractionnelles de l'EEG provenant de l'analyse spectrale de l'électroencéphalogramme et la profondeur du coma mesurée cliniquement avec l'échelle "Glasgow Coma Score", et d'évaluer l'exactitude de l'AS dans la prédiction de l'évolution à long terme. Trente-deux patients devenus inconscients à la suite d'un traumatisme crânien par contusion (GCS moyen $=7$ ) ont eu des enregistrements EEG intermittents quotidiens de $1-10$ jours après le traumatisme. Il existait une corrélation significative entre l'amplitude fractionnelle de l'EEG et le GCS. Le taux et l'ampleur des changements de l'EEG et du GCS étaient également en corrélation. Il y avait des différences significatives dans les paramètres de l'AS entre le groupe des patients qui s'étaient améliorés et celui des patients qui s'étaient détériorés à la fin de la période de surveillance $(\mathrm{p}=.0222)$ ainsi que dans la modification des paramètres dans le temps $(p=.0186)$. En utilisant l'analyse linéaire discriminante des paramètres de l'AS, la précision du pronostic était de $80 \%$ (estimée rétrospectivement). Une classification précise de l'issue à long terme a été possible dans un certain nombre de cas chez qui il n'y avait pas de changement dans le GCS pendant la période de surveillance.

Can. J. Neurol. Sci. 1988; 15:82-86

Monitoring of the neurologic function of comatose headinjured patients has traditionally been carried out by the use of an abbreviated version of the neurologic exam, usually consisting of a measure of the depth of coma (i.e. the Glasgow Coma Score) ${ }^{\prime}$ and one or several measures of brainstem function (i.e. pupillary reaction, oculocephalic responses, etc.). In the deeper levels of coma the assessment of level of consciousness becomes restricted to the observation of a few stereotyped motor responses to painful stimuli. At this level of coma it is possible that significant change may occur in the patient's neurologic status before this is measurable by the clinical neurologic examination.
The problem of monitoring depth of coma is further compounded when patients requiring ventilator support for respiratory care or the control of raised ICP must be sedated and or pharmacologically paralysed to facilitate ventilator management. The development of an objective, quantitative, on-line measure of neurologic status is therefore desirable for its immediate clinical benefit as a monitoring tool, its potential use in the study of the relation of neural function to physiological parameters such as intracranial pressure, and in monitoring the efficacy of standard or new treatment modalities in head-injured patients during the acute treatment phase.

From the Division of Neurosurgery. University of Toronto (Dr. Moulton); the Department of Neurosurgery, Soroka Medical Centre. Beer-Sheeba, Israel (Dr. Ronen); the Department of Neurosurgery, University Federal of Goias, Brazil (Dr. Desalles); the Hospital N.S. da Paz, S.J. do Rio Preto, Sao Paulo, Brazil (Dr. Maset); Medical College of Virginia, Virginia Commonwealth University, Richmond (Drs. Marmarou, Ward, Choi, Lutz, Byrd, Muizelarr and Young)

Reprint requests to: Dr. R. Moulton, Division of Neurosurgery, University of Toronto, St. Michael's Hospital, 38 Shuter St., Toronto, Ontario, Canada M5B 1A6 
The background frequency of the electroencephalogram (EEG) and changes therein have been shown in a number of studies to be related to the level of consciousness. ${ }^{2 \cdot 7}$ The large amount of data produced by the standard paper chart EEG and the requirement for expert interpretation of the data have worked against the adoption of conventional EEG as a monitoring tool. One approach to these problems, made possible by advances in microcomputer technology, is the continuous characterization of the EEG in the frequency domain by use of the Fast Fourier Transform. ${ }^{8}$ Power spectral analysis (PSA) provides a concise electronic summary of quantitative information on the background frequencies and amplitude of the EEG. The output may be either graphic or numeric with the latter being well-suited to statistical analysis. ${ }^{9}$ The data compression and simplification of analysis make PSA attractive for use as a monitoring tool in the intensive care setting.

The present study was designed as a preliminary assessment of the usefulness of this technique in monitoring comatose head-injured patients. The objectives of the study were twofold: first we wished to confirm in a quantitative manner the relationship between the background frequency of the EEG and the depth of coma; secondly, we wished to define the relationship between spectral parameters of the EEG, their change over time, and patients' clinical outcomes.

\section{Clinical Material and Methods}

The patient group consisted of 32 patients rendered unconscious by blunt head injury. Mean GCS at admission was 7 (mode $=5$ ). The age range of the patients was from 6 to 62 years. The mean age was 27.4 years. Twelve of the patients had well-defined mass lesions such as extra-axial haematomas or brain contusions. Eleven of these were treated by craniotomy and evacuation of the mass. Five patients died, four from uncontrollable intra-cranial pressure. All patients were cared for in the neurosurgical intensive care unit according to a standardized head injury protocol. ${ }^{10}$ Neurologic examination was carried out at least once daily. The examination consisted of the GCS and assessment of the pupillary, oculocephalic, and corneal responses. The duration of patient follow-up for outcome determination was at least six months in all patients.

EEG recording was carried out following admission to the ICU, either from the emergency room or postoperatively. The average duration of monitoring was 4.5 days. All patients were monitored for at least two days. EEG recording was terminated when the patient either regained consciousness, died, or the neurologic state was clinically unchanged over several days.

Ten to thirty minutes of EEG per day were recorded onto magnetic tape at one to four hourly intervals. The four channels used were $\mathrm{C} 3, \mathrm{C} 4,01$, and 02 to linked ears. The EEG was inspected at the time of recording and playback to eliminate recordings containing artefact. The Fourier analysis was done off-line using a microcomputer system. The analysis was based on the fractional amplitudes in four frequency bands: delta (1-3 hz.), theta (4-7 hz.), alpha (8-12 hz.), and beta (13-30 hz). Two second epochs of EEG were used and the sampling frequency was $128 \mathrm{hz}$.

\section{Data Analysis}

In order to attempt to quantify the strength of the relationship between the background frequency of the EEG and level of consciousness observed clinically, multiple regression was carried out for the first and second days post injury, and on the final day of monitoring. The latter was the day on which monitoring was discontinued either because the patient had died, regained consciousness, or was clinically unchanged for a number of days. The PSA values for each day were averaged and compared with the GCS for the same day in each patient. The channel containing the highest percentage of high frequency activity (i.e. alpha and beta) and the least low frequency activity was chosen for comparison in order to obviate the effects of localized disturbances in the EEG, which were present in a number of patients with focal pathology. This was especially striking in two patients whose GCS ranged from 9-14 and 10-15 and who had well defined hemispheric neurologic deficits (dysphasia and hemiplegia). Both of these patients had a large discrepancy in the amount of slowing between the injured and uninjured hemispheres (greater slowing on the injured side). This discrepancy increased as the patients regained consciousness. The magnitude of change in the GCS was correlated with that of the PSA by subtracting the initial day values of each from the final day values. Similarly the rate of change was estimated by dividing the magnitude of change by the number of days monitored.

Outcome was classified according to the Glasgow Outcome Scale determined at six months post-injury. "Improved patients were those with a good or moderate outcome. Conversely, deteriorated patients were those who were dead, severely disabled, or vegetative at six months post-injury. Multivariate T-squared tests and linear discriminant analysis were used to contrast the differences between the improved and deteriorated patient groups, and to estimate the accuracy of outcome prediction using parameters derived from PSA.

Multiple regression, multivariate T-squared tests, and linear discriminant analysis procedures were carried out using the SAS statistical package. Significance testing of the outcome classification error rate was done using the Chi-squared test with Yate's correction.

\section{Results}

\section{Correlation Data}

The results of the correlation analyses are presented in Tables 1-5. All correlations are reported for the group as a whole, and for the diffuse injury and mass lesion subgroups. The statistical programme selected the best one to three variable models. The fourth variable (i.e. fourth frequency band) is linearly related to the other three so its inclusion does not add any new information. The correlation coefficients and their probability values are given for each model.

There is a significant correlation between the GCS and the fractional amplitude of the EEG determined by PSA. If one looks at the frequency bands individually, delta is inversely correlated with GCS and alpha and beta are positively correlated. The delta frequency band $(1-3 \mathrm{hz}$.) appeared to be the best 


\begin{tabular}{rrrr}
\hline \multicolumn{4}{l}{ Table 1: Correlation of PSA Parameters with GCS - Initial Day. } \\
\hline \hline Model & $\begin{array}{c}\text { All Patients } \\
(\mathbf{n}=\mathbf{3 2})\end{array}$ & $\begin{array}{c}\text { Mass Lesions } \\
(\mathbf{n}=\mathbf{1 2})\end{array}$ & $\begin{array}{c}\text { Diffuse Injury } \\
(\mathbf{n}=\mathbf{2 0})\end{array}$ \\
\hline 1 Variable & $\mathrm{D}^{*}$ & $\mathrm{D}$ & $\mathrm{D}$ \\
$\mathrm{r}$ & .43 & .51 & .48 \\
$\mathrm{p}$ & .01 & .09 & .03 \\
2 Variable & $\mathrm{D}, \mathrm{B}$ & $\mathrm{D}, \mathrm{B}$ & $\mathrm{D}, \mathrm{T}$ \\
$\mathrm{r}$ & .44 & .55 & .48 \\
$\mathrm{p}$ & .04 & .19 & .10 \\
3 Variable & $\mathrm{D}, \mathrm{T}, \mathrm{A}$ & $\mathrm{D}, \mathrm{T}, \mathrm{B}$ & $\mathrm{D}, \mathrm{A}, \mathrm{B}$ \\
$\mathrm{r}$ & .44 & .61 & .48 \\
$\mathrm{p}$ & .10 & .27 & .23 \\
\hline
\end{tabular}

* $\mathrm{A}=$ Alpha, $\mathrm{B}=$ Beta, $\mathrm{D}=$ Delta, $\mathrm{T}=$ Theta (relative amplitudes)

\begin{tabular}{rrcr}
\hline \multicolumn{3}{l}{ Table 2: Correlation of PSA Parameters with GCS - Second Day. } \\
\hline \hline Model & $\begin{array}{c}\text { All Patients } \\
(\mathbf{n}=\mathbf{3 2})\end{array}$ & $\begin{array}{c}\text { Mass Lesions } \\
(\mathbf{n}=\mathbf{1 2})\end{array}$ & $\begin{array}{c}\text { Diffuse Injury } \\
(\mathbf{n}=\mathbf{1 9})\end{array}$ \\
\hline 1 Variable & $\mathrm{B}^{*}$ & $\mathrm{D}$ & $\mathrm{B}$ \\
$\mathrm{r}$ & .67 & .56 & .72 \\
$\mathrm{p}$ & .0001 & .06 & .0005 \\
2 Variable & $\mathrm{T}, \mathrm{B}$ & $\mathrm{D}, \mathrm{B}$ & $\mathrm{T}, \mathrm{B}$ \\
$\mathrm{r}$ & .71 & .59 & .75 \\
$\mathrm{p}$ & .0001 & .14 & .001 \\
3 Variable & $\mathrm{D}, \mathrm{T}, \mathrm{A}$ & $\mathrm{D}, \mathrm{T}, \mathrm{A}$ & $\mathrm{D}, \mathrm{A}, \mathrm{B}$ \\
$\mathrm{r}$ & .71 & .60 & .76 \\
$\mathrm{p}$ & .0003 & .30 & .005 \\
\hline
\end{tabular}

* $\mathrm{A}=$ Alpha, $\mathrm{B}=$ Beta, $\mathrm{D}=$ Delta, $\mathrm{T}=$ Theta (relative amplitudes)

\begin{tabular}{lccc}
\hline Table 3: Correlation of PSA Parameters with GCS - Final Day. \\
\hline \hline Model & $\begin{array}{c}\text { All Patients } \\
(\mathbf{n}=\mathbf{3 2})\end{array}$ & $\begin{array}{c}\text { Mass Lesions } \\
(\mathbf{n}=\mathbf{1 2})\end{array}$ & $\begin{array}{r}\text { Diffuse Injury } \\
(\mathbf{n}=\mathbf{2 0})\end{array}$ \\
\hline 1 Variable & $\mathrm{D}^{*}$ & $\mathrm{~A}$ & $\mathrm{D}$ \\
$\mathbf{r}$ & .76 & .82 & .81 \\
$\mathrm{p}$ & .0001 & .001 & .0001 \\
2 Variable & $\mathrm{D}, \mathrm{B}$ & $\mathrm{A}, \mathrm{B}$ & $\mathrm{D}, \mathrm{A}$ \\
$\mathrm{r}$ & .79 & .90 & .85 \\
$\mathrm{p}$ & .0001 & .0005 & .0001 \\
3 Variable & $\mathrm{T}, \mathrm{A}, \mathrm{B}$ & $\mathrm{D}, \mathrm{A}, \mathrm{B}$ & $\mathrm{T}, \mathrm{A}, \mathrm{B}$ \\
$\mathrm{r}$ & .79 & .91 & .86 \\
$\mathrm{p}$ & .0001 & .002 & .0001 \\
\hline
\end{tabular}

* $\mathrm{A}=$ Alpha, $\mathrm{B}=$ Beta, $\mathrm{D}=$ Delta, $\mathrm{T}=$ Theta (relative amplitudes)

Table 4: Correlation of the Magnitude of Change* in the PSA and GCS.

\begin{tabular}{rccc}
\hline \hline Model & $\begin{array}{c}\text { All Patients } \\
(\mathbf{n}=\mathbf{3 2})\end{array}$ & $\begin{array}{c}\text { Mass Lesions } \\
(\mathbf{n}=\mathbf{1 2})\end{array}$ & $\begin{array}{c}\text { Diffuse Injury } \\
(\mathbf{n}=\mathbf{2 0})\end{array}$ \\
\hline 1 Variable & $\mathrm{B}^{* *}$ & $\mathrm{~T}$ & $\mathrm{D}$ \\
$\mathrm{r}$ & .62 & .77 & .61 \\
$\mathrm{p}$ & .0001 & .003 & .005 \\
2 Variable & $\mathrm{A}, \mathrm{B}$ & $\mathrm{D}, \mathrm{T}$ & $\mathrm{D}, \mathrm{A}$ \\
$\mathrm{r}$ & .64 & .81 & .67 \\
$\mathrm{p}$ & .0005 & .009 & .004 \\
3 Variable & $\mathrm{D}, \mathrm{A}, \mathrm{B}$ & $\mathrm{D}, \mathrm{A}, \mathrm{B}$ & $\mathrm{D}, \mathrm{A}, \mathrm{B}$ \\
$\mathrm{r}$ & .64 & .81 & .70 \\
$\mathrm{p}$ & .002 & .03 & .01 \\
\hline
\end{tabular}

* Magnitude of change was determined by subtracting initial day from final day values.

** $\mathrm{A}=$ Alpha, $\mathrm{B}=$ Beta, $\mathrm{D}=$ Delta, $\mathrm{T}=$ Theta (relative amplitudes)

\begin{tabular}{rccc}
\hline \multicolumn{2}{l}{ Table 5: Correlation of the Rage of Change* in the PSA and GCS. } \\
\hline \hline Model & $\begin{array}{c}\text { All Patients } \\
(\mathbf{n}=\mathbf{3 2})\end{array}$ & $\begin{array}{c}\text { Mass Lesions } \\
(\mathbf{n}=\mathbf{1 2})\end{array}$ & $\begin{array}{c}\text { Diffuse Injury } \\
(\mathbf{n}=\mathbf{2 0})\end{array}$ \\
\hline 1 Variable & $\mathrm{B}^{* *}$ & $\mathrm{~B}$ & $\mathrm{D}$ \\
$\mathrm{r}$ & .58 & .76 & .64 \\
$\mathrm{p}$ & .0005 & .005 & .002 \\
2 Variable & $\mathrm{A}, \mathrm{B}$ & $\mathrm{D}, \mathrm{T}$ & $\mathrm{D}, \mathrm{T}$ \\
$\mathrm{r}$ & .62 & .80 & .70 \\
$\mathrm{p}$ & .001 & .01 & .003 \\
3 Variable & $\mathrm{D}, \mathrm{T}, \mathrm{A}$ & $\mathrm{D}, \mathrm{T}, \mathrm{B}$ & $\mathrm{D}, \mathrm{A}, \mathrm{B}$ \\
$\mathrm{r}$ & .62 & .81 & .72 \\
$\mathrm{p}$ & .003 & .03 & .007 \\
\hline
\end{tabular}

* Rate of change was determined by subtracting initial day values from final day values and dividing by the number of days monitored.

** $\mathrm{A}=$ Alpha, $\mathrm{B}=$ Beta, $\mathrm{D}=$ Delta, $\mathrm{T}=$ Theta (relative amplitudes)

single correlate of the depth of coma. More information was obtained by correlation with two frequency bands. Little improvement was obtained by employing more than two frequency bands.

The day by day correlation with GCS improves over time, both for the group as a whole and for the subgroups. Dawson et al reported a lag between the onset of clinical changes in headinjured patients and their manifestation in the EEG. ${ }^{12}$ The correlation data herein may in part be a reflection of that phenomenon. Another factor is that there is a greater range in the GCS among the patient cohort during the second and final days of the study, accounting for some of the improvement in the correlation coefficients.

The rate and magnitude of change in the GCS and PSA are also significantly correlated. This indicates that those patients having the largest and most rapid changes in their level of consciousness have the largest and most rapid changes in the EEG.

All the correlations were substantially improved by segregation of patients according to injury type (i.e. diffuse injury or mass lesion) implying differing effects of different injury types on the EEG generators (see Figure 1). The tendency was for the diffuse injury group to have an equal or greater amount of slowing of the EEG than the mass lesion group, in spite of the fact that the latter group had a lower mean GCS at all times.

\section{OUTCOME ANALYSIS}

Table 6 shows the characterization of spectral parameters for the improved and deteriorated patient groups on the initial and final days of monitoring, and the change in these parameters over time. Only three variables were compared due to the linear relationship between the variables (i.e. by knowing any three variables the fourth can always be exactly calculated). There is no difference between the groups on the initial day. There is a statistically significant difference on the final day $(p=.02)$. The change in PSA parameters over time is also significant $(p=$ .02 ). Those patients who deteriorated showed an increase in slow activity and a decrease in fast activity.

Figure 2 illustrates the error rate for outcome classification derived from linear discriminant analysis using the "jacknife" method of error estimation. The minimum number of parameters giving the optimal prediction accuracy were used. The PSA parameters were the change in fractional delta over time and 


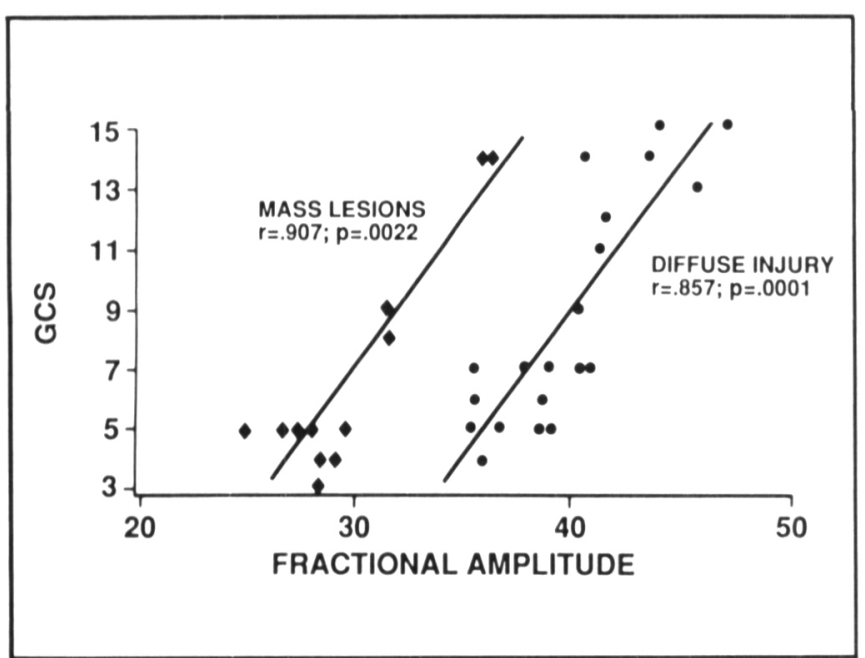

Figure I - Final day regression plot of GCS vs PSA by lesion type - This figure shows the separate regression lines obtained on the final day of monitoring for patients with mass lesions (left line, diamonds) and patients with diffuse injuries (right line, stars). The units on the $Y$ axis are the GCS measured clinically. Those on the $X$ axis are a dimensionless measure derived from the three variable regression equation for the final day data. The presence of two quite distinct regression lines implies a different effect of the two injury types on the EEG generators.

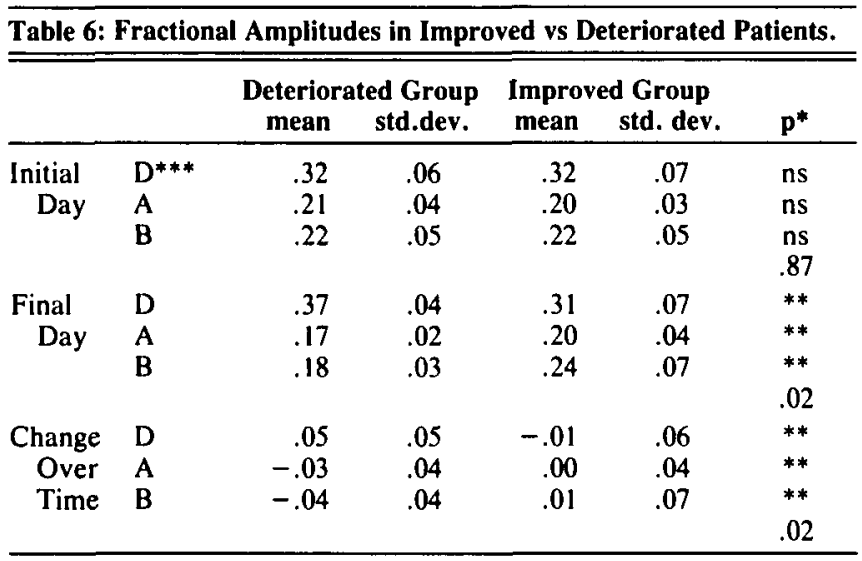

* The numeric $p$ value is derived from the multivariate T-squared test which controls for overall error for three variables.

** Indicates a $\mathrm{p}<.05$ for individual comparisons.

*** $\mathrm{A}=$ Alpha, $\mathrm{B}=$ Beta, $\mathrm{D}=$ Delta.

the final fractional amplitude of beta. The error rate was $25 \%$, $.01>p>.005$. Of a total of eight errors seven were falsely pessimistic (i.e. patients who improved were erroneously classified into the deteriorated group). In three cases this occurred when the patients suffered reversible complications (e.g. uraemia, sepsis) which produced transient neurologic worsening (reflected accurately in the PSA), but from which the patients ultimately made a good recovery.

\section{Discussion}

There is a substantial literature regarding EEG findings in coma of varying aetiology, including head injury. In general these show that the most common changes are slowing of the

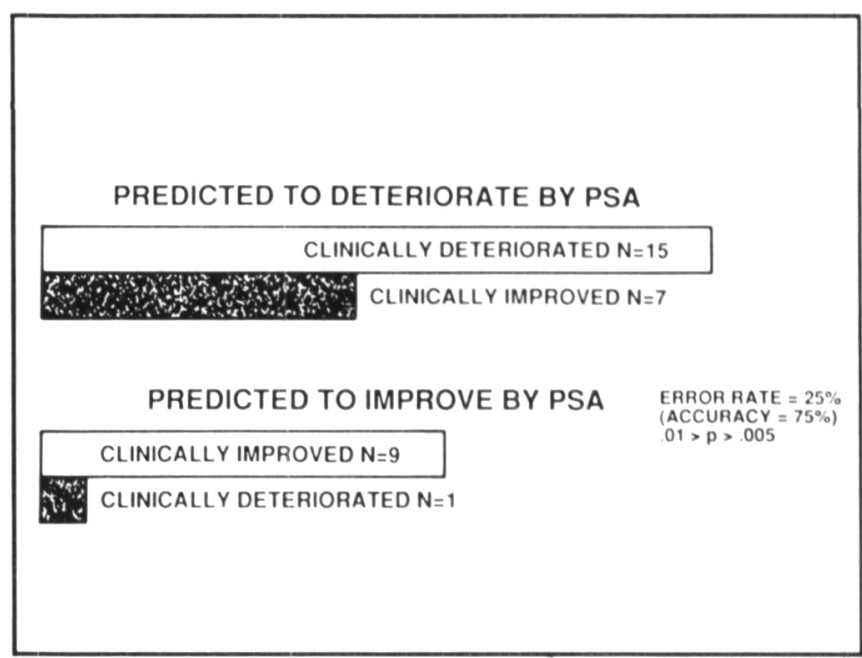

Figure 2 - Prediction Accuracy of Power Spectral Analysis (PSA) - This graph illustrates the accuracy of outcome prediction (improved or deteriorated) in individual patients. The light bars indicate the number of correct predictions, and the dark bars indicate the number of errors. The PSA parameters used to generate the predictions were the change in fractional delta over time and the final fractional value of beta.

background frequencies. Furthermore, changes in the depth of coma tend to be paralleled by changes in the background frequencies with increased slowing occurring with increasing depth of coma. ${ }^{2-7} \mathrm{~A}$ common feature of these studies is their reliance on a qualitative interpretation of the pattern characteristics of the EEG. One problem with this method is the limited quantitative resolution in terms of the relative or absolute amount of amplitude in a given frequency band. Over an average period of 4.5 days the difference in the amount of change in the delta frequency band in those patients who deteriorated and those who improved was in the neighbourhood of $6 \%$. This is very likely beyond the resolution of visual interpretation of the standard EEG record, yet represents a statistically significant difference in this patient population.

Our data tend to confirm the observations recorded in the literature on the frequency characteristics of the EEG in coma (i.e. the amount of slowing of the background frequencies of the EEG is proportional to the depth of coma). Furthermore the rate and magnitude of change in the EEG was significantly correlated with the rate and magnitude of change in the depth of coma measured clinically. This suggests that the depth of coma and changes therein may be objectively quantified by PSA.

Characterization of the mean fractional amplitudes of the EEG power spectrum at the initiation and termination of monitoring failed to show any significant differences in outcome groups at the start of monitoring, but was significant at the termination of monitoring (usually 3-6 days later). This feature suggests the presence of transient reversible damage in those patients who improve, and/or potentially salvageable function in those who go on to deteriorate.

The correlation data confirm the general relationship of the spectral parameters of the EEG to the depth of coma and the magnitude and rate of change therein. The outcome analysis addresses the issue of the accuracy of the technique in predicting the outcome of individual patients. Bricolo et al has reported on the prognostic value of both the EEG and power spectral 
analysis in coma. He found that spontaneous and induced variability in the EEG and power spectrum were associated with a good prognosis. The analysis of the power spectrum was a qualitative one based on a graphic presentation of the data (i.e. Compressed Spectral Array). ${ }^{13.14}$ Based on a similar sort of qualitative analysis of the CSA, Sironi et al found a difference in mortality in groups with different types of CSA patterns. ${ }^{15}$ More recently the persistence or return of a peak in the CSA display between 4 and $13 \mathrm{hz}$. during the first 10 days of coma has been associated with a good recovery. ${ }^{16}$ Steudel et al described the relationship of quantitative parameters of the EEG power spectrum to prognosis in 50 adult patients with severe brain injuries. He found that an increase in the absolute and relative values of alpha and theta during the first week was associated with survival. ${ }^{17}$ Karnaze et al found that the prognostic capability of the CSA based on the presence of spontaneous alteration in the amplitude or frequency was equivalent to the GCS. ${ }^{18}$

The accuracy of outcome prediction in this study was $75 \%$. Most of the errors were of the falsely pessimistic variety (seven or eight errors). In three of these cases the patients suffered reversible neurologic setbacks from which they went on to make a good recovery. The transient neurologic decline of these patients was accurately reflected in the PSA. Therefore as an estimate of monitoring accuracy, the quoted error rate (i.e. $25 \%$ ) based on outcome prediction is likely overly pessimistic.

Although the prognosis was self-evident in the four patients who died early in uncontrollable ICP and in those who rapidly regained consciousness, in 16 patients the GCS changed by one or less during the period of monitoring (10/16 had no change). The accuracy of outcome prediction in this subgroup with minimal or no change in the clinical neurologic examination was $80 \%$, suggesting that the PSA may in fact be a more sensitive measure of neurologic function in comatose patients than the clinical examination.

Future analysis of the utility of PSA as a real-time monitor of neurologic status in comatose head-injured patients will require the prospective collection of continuous PSA data and its comparison with clinically measured changes in patient status in order to determine which occur first. One of the anticipated difficulties of such a study is the postulated lack of sensitivity of the clinical neurologic examination in the comatose patient. One possible way around this difficulty is the provision of corroborative evidence of deteriorating cerebral function, perhaps using measurement of cerebral blood flow and metabolism, or biochemical markers of cerebral metabolic function. The effects of sedative drugs and variations in physiologic parameters such as PC02 and ICP on the EEG must also be carefully studied in this patient population.

\section{CONCLUSION}

Based on an off-line analysis of the fractional amplitude of the EEG generated by power spectral analysis, we conclude that quantitative measurement of the background frequencies of the EEG is significantly correlated with the level of consciousness determined clinically, and is accurate in predicting the outcome. These results indicate the potential use of the technique in monitoring comatose head-injured patients in the ICU. Definitive demonstration of the usefulness of the technique will require a prospective study using continuously collected EEG data.

\section{ACKNOWLEDGEMENTS}

This work was supported in part by Grant NS- 125787 from the National Institutes of Health, the Richard Roland Reynolds Neurosurgical Research Laboratories, and a special grant from the Office of the Vice-President for Health Sciences at the Medical College of Virginia in Richmond.

\section{REFERENCES}

1. Teasdale G, Jennett B. Assessment of coma and impaired consciousness: A practical scale. Lancet 1974; 2: 81-84.

2. Courjon J. Traumatic disorders. In: Remond A, ed. Handbook of Electroencephalography and Clinical Neurophysiology. Amsterdam: Elsevier 1972; 14: 14b-8-39.

3. Hansotia P, Gottschalk P, Green P, et al. Spindle coma: Incidence, clinicopathologic correlates, and prognostic value. Neurology (NY) 1981; 31: 83-87.

4. Harner R, Naquet R. Altered states of consciousness, coma, cerebral death. In: Remond A, ed. Handbook of Electroencephalography and Clinical Neurophysiology. Amsterdam: Elsevier 1975; 12: 12-5-23

5. Rumpl E, Lorenzi E, Hackl JM, et al. The EEG at different stages of acute secondary traumatic midbrain and bulbar brain syndromes. Electroencephalogr Neurophysiol 1979; 46: 487-497.

6. Silverman D. Restrospective study of the EEG in coma. Electroencephalogr Clin Neurophysiol 1963; 15: 486-503.

7. Stockard JJ, Bickford RG, Aung MH. The electroencephalogram in traumatic brain injury. I $n$ : Vinken RJ, Bruyn GW, eds. Injuries of the brain and skull. Handbook of Clinical Neurology. Amsterdam: Elsevier 1975; 1: 317-367.

8. Bickford RG. Computer analysis of background activity. In: Remond A, ed. EEG Informatics. A Didactic Review of Methods and Applications of EEG Data Processing. Amsterdam: Elsevier 1977: $215-232$.

9. Bronzino JD. Quantitative analysis of the EEG - general concepts and animal studies. IEEE Trans Biomed Eng. 1984; (BME-31) 12: 850-856.

10. Becker DP, Miller JD, Ward JD, et al. The outcome from severe head injury with early diagnosis and intensive management. J Neurosurg 1977; 47: 491-502.

11. Jennett $B$, Bond $M$. Assessment of outcome after severe brain damage: A practical scale. Lancet 1975; 1: 480-484.

12. Dawson RE, Webster JE, Gurdjian ES. Serial electroencephalography in acute head injuries. J Neurosurg 1951; 8: 613-630.

13. Bricolo A. Electroencephalography in neurotraumatology. Clinic Electroencephalogr 1976; 7: 184-197.

14. Bricolo A, Turazzi S, et al. Clinical application of compressed spectral array in long-term EEG monitoring of compatose patients. Electroencephalogr Clin Neurophysiol 1978; 45: 211-225.

15. Sironi VA, Ravagnati L, et al. Diagnostic and prognostic value of EEG compressed spectral analysis in post-traumatic coma. In: Villani R, Papo I, et al., eds. Advances in Neurotraumatology. Milan: Elsevier 1982: 79-84.

16. Can BR, Shaw NA. Monitoring by compressed spectral array in prolonged coma. Neurology (Cleveland) $1984 ; 34: 35-39$.

17. Steudel WI, Kruger J. Using the spectral analysis of the EEG for prognosis of severe brain injuries in the first post-traumatic week. Acta Neurochir Suppl 1979; 28: 40-42.

18. Karnaze DS, Marshall LF, Bickford RG. EEG monitoring of clinical coma: The compressed spectral array. Neurology (NY) 1982; 32: 289-292. 